\title{
Harnessing students' diversities for effective instruction in inclusive classes: The case of Zimbabwe's Secondary Schools
}

\author{
Dr. Onias Mafa \\ Faculty of Arts and Education, Zimbabwe Open University.
}

\begin{abstract}
In view of the current movement towards inclusive education and education for all which means having students with special educational needs in the regular classrooms rather than special schooling, it has become imperative to find a workable solution that will benefit all students. This study focuses, from a didactic (teaching and learning) perspective; on how teachers can optimise inclusion for effective instruction. The study adopted a qualitative methodology, which made use of case study research design. Twenty five secondary school teachers from Bulawayo urban were purposively sampled. Focus group discussions and face-to-face interviews were used for data generation. Findings were that while teachers were aware of student diversities, and teaching strategies that could be used to exploit student diversities, they were not harnessing student diversities. Reasons were: time factor in relation to syllabi coverage; demanding nature of student-centred teaching methods; lack of resources; nature of student assessment and teachers' limited skills. Recommendations were that: there is need for pro-inclusive teacher development programmes; increasing resource availability including well equipped libraries and rethinking student assessment.
\end{abstract}

Key terms: students' diversities, inclusive classes, effective instruction, secondary schools

\section{Introduction}

The debate on how students of different academic abilities should be organised and taught is probably as old as the introduction of formal schooling in communities. This debate has divided the world of educational research into two distinct camps. On one hand, researchers such as Green (2002) and Mann (2002) and associations such as the National Association of School Psychologists (NASP) (2002) support inclusion. The aforementioned sources argue that inclusion affords all students equal educational opportunities regardless of their differences in intellectual abilities, special educational needs, gender, race and social class.

On the other hand, some educators, researchers and scholars draw from different ethical arguments to support ability grouping. They argue that high ability students languish in inclusive classes (Loveless 1998), and that if grouping programmes entail substantial adjustment of curriculum to meet students' abilities, clear, positive effects are realised by the learners (Kulik 1992). However, those educational researchers on the fence argue that the findings from the opposing camps are not conclusive. They further point out that whatever benefits or disadvantages a particular grouping method has, cannot be ascribed only to the grouping method in question, since the effects of other variables that cannot be held constant come into play (Riehl 2000). This camp suggests that findings should be viewed with caution. Lamenting on the protracted grouping debate, Farmer (1996: online) states that:

The tragic extents of the debate are probably epitomized on the one hand by students

'labelled' at enrolment to the point that their educational paths are fully determined, and on the other by students clearly in need of a particular educational program but denied it on the basis that all students, no matter how different they and their needs may be, should be provided with the "same education".

It therefore appears that the problem is how to come up with a solution for teaching inclusive classes. In view of the current movement towards inclusive education and education for all which means having students with special educational needs in the regular classrooms rather than special schooling it has become imperative to find a workable solution that will benefit all students. This present study focuses from a didactic (teaching and learning) perspective, on how teachers can harness students' differences to bring about effective teaching and learning in an inclusive class. It was informed by the following questions:

- How can teachers harness students' diversities to make their teaching effective?

- To what extent are teachers making use of students' diversities in their teaching?

- If teachers are not making extensive use of students' diversities, what could be the possible reasons?

\subsection{Background to the problem}

Globally, the issue of organising students for instructional purposes is receiving a lot of attention from researchers. Questions of Whether, When and How to group students for instructional purposes are global and represent some of the most difficult and frustrating challenges facing educators today (Susan 1991). This is 
because students come into class with different levels of knowledge, skills, learning rates and motivation and are from a wide variety of social and cultural backgrounds (Slavin 1994; Killen 2002). Students' diversities require teachers to adopt appropriate levels of instruction. This imposes strains and hard decisions on the teacher (Vivian 2001).

Attempting to cater for individual differences during instruction is one of the fundamental problems dogging education and often culminates in politically and emotionally charged policies (Shield 1996). At one time, heavy emphasis was on creating homogeneity among students. A number of questions have been raised as to whether this is a good pedagogical practice. Answers depend on one's position on the ability grouping continuum. However, the emerging trend is to view learner diversity as a resource rather than a liability. Good and Brophy (1997:311) state that:

... students with different backgrounds can interact with one another and learn how the same text material or concept can be interpreted differently by persons from different backgrounds.

Thus teachers can use unique student experiences to make classroom learning richer and more sensitive to differences among students . . . . Although widely diverse groups of learners complicate teaching in some respects, most instruction should occur in heterogeneous settings.

Riehl (2000) cites a number of authors on culturally responsive teaching who support the premise that culturally diverse students pose opportunities instead of teaching problems.

\subsection{Benefits of Classes having Diverse Students}

The bone of contention between proponents of inclusion and ability grouping has been in effect, over the question of which grouping plan results in better conditions for teaching and learning. Studies of grouping have focused on academic achievement, social and affective outcomes and classroom instructional strategies in an attempt to determine to what extent different grouping arrangements may be associated with different student outcomes.

\subsubsection{Academic achievement outcomes}

Many educators object to creating homogeneity among students on philosophical grounds. They are of the view that educational outcomes should be assessed not only in terms of their efficiency, but also in terms of equity. These educators value diversity, policies of inclusion and practices that meet the needs of all students. According to Good and Brophy (1997) the benefits of inclusion are that:

- Inclusive classes are just as effective as homogeneous classes for accomplishing the achievement of other cognitive objectives.

- Inclusive classes achieve student-student interaction, which according to social constructivist theories of teaching and learning view learning as a social construction of new understandings accomplished primarily through sustained discussion.

Seemingly high academic outcomes by students in high ability classes result from enriched curriculum, which if availed to students in low ability classes will yield high achievements, as well. The NASP (2002) states that if properly implemented, inclusion offers advantages which are not available in ability-grouped schools. First, it promotes higher expectations for student achievement. Second, it enables students to learn from their peers, including students whose background may be very different from their own. Third, it emphasises effort more than ability.

Students from different experiential backgrounds, with divergent views can undoubtedly raise the discourse to high academic levels for the benefit of all. The researcher concurs with the documented academic achievement outcomes of inclusion and would like to point out that enriched curriculum alone is not responsible for high achievement. Such a curriculum should be complemented with appropriate teaching strategies that take into cognisance the students' uniqueness.

\subsubsection{Organisational and instructional strategies}

The NASP (2002) identifies two benefits that inclusion has on organisation and instructional delivery: First, all students have equal access to an enriched curriculum and the highest quality instruction schools have to offer. Second, it encourages teachers to accommodate individual differences in students' instructional and social needs. This is contrary to teachers' behaviour in low ability classes where they give students less exposure to essential knowledge and skills (Lockwood and Cleveland 2001). Teachers dislike teaching lowability classes, spend less time preparing for them, and give them less varied interesting and challenging activities (Oakes 1992).

The researcher assents with Gamoran, Nystrand, Berends and Lepore (1995) argument that there is no consensus as to what is the best method of teaching. Therefore, it does not necessarily follow that students of the same ability ought to be taught using the same teaching method. On the same note, it is not always the case 
that students who perform at the same level have the same learning styles and speeds. These variables mean that students must be taught differently. This realisation strengthens the case for inclusion. Inclusion is compatible with the concept of multiple intelligences as propounded by Gardner (Wilson 1998). It encourages teachers to employ student-centred teaching strategies. Thus it is presumptive that such strategies may assist students to own the information, process it and transfer it to their long-term memories, resulting in improved academic performance across all the different ability levels.

\subsubsection{Affective and social outcomes}

Commenting on labelling, Reid, Clunies-Ross, Goacher and Vile (1981) report that inclusion has advantages for teachers too in that, without 'bottom' classes you avoid 'bottom' teachers. This may improve teacher morale and general attitudes towards work, since it has been observed that labelling effects permeate the entire school and social culture (Oakes and Lipton 1999).

Inclusive classes are more effective for accomplishing affective and social outcomes, such as promoting cultural understanding and pro-social and affective goals (Good and Brophy 1997). Ireson and Hallam (2001) state that such goals include: encouraging cooperative behaviour and social integration; promoting good relations between students; enhancing student-teacher interactions; reducing some of the competition engendered by structured grouping; and providing a sense of continuity and security for primary students when they proceed to secondary school.

Inclusion gives students a 'fresh start'. Reference is also made to results of teacher expectation and attempting to predict performance at this stage, the halo effect, self-fulfilling prophecies, self-perpetuating labelling, writing children off, children's acceptance of a social pattern following labelling, and the need to delay emphasising differences until as late as possible (Reid et al. 1981).

Marcus and Johnson (1998) and Shield (1996) accentuate that in this ever increasingly diverse society, it hardly makes sense to keep young children from developing interpersonal and intergroup understanding that come from the experience and close working relationship with those who are different. The NASP (2002) notes that inclusion avoids stigmatising students with lower ability and reduces in-school segregation based on socioeconomic status, race, gender, ethnicity, or disability. The main economic argument for inclusion is that all children need strengthened education to meet the challenges of the twenty-first century (Marcus and Johnson, 1998).

\subsection{Challenges of Teaching Classes having Diverse Students}

The needs of gifted and talented students cannot be adequately addressed in inclusive classes (Farmer, 1996). Dean (1997) argues that the move to inclusion will have a detrimental effect on the gifted students. He states that unless such students are freed from the restraints of mediocre classrooms and given the chance to excel they will never be truly able to achieve up to their potential. Proponents of ability grouping are concerned by a lack of academic texture and the view that in inclusive classes, able students would not be extended (Reid et al. 1981). They think that without the stimulation of able peers, the faster ones soon slow down, and the outcome will be that the most able sink to a happy mean and, soon learn to accept a lower standard of work.

Hallahan and Kauffman (1997) acknowledge that while cooperative learning, peer tutoring, and other arrangements for addressing individual differences in inclusive classes may meet the needs of most students, they come short when it comes to addressing the special needs of some students, for example the gifted. They contend that maintaining the challenge for and demanding excellence of all students is an extraordinary challenge in inclusive classes, which many teachers may find a daunting and overwhelming task.

Low ability students experience tragic mental and physical elimination in inclusive classes. Such students may fail to make progress (Fuchs, Fuchs and Fernstrom 1993). The end result is an ever-increasing gap between student achievements at different performance levels. Teachers may be inclined to think that they are ill-equipped to stand up to the task of dealing competently with the students' diversity. Collier (1982) sums the shortfalls of inclusion as that:

- Teaching inclusive classes can only be successful where resources are adequate, without which attempting it results in paying lip service.

- During class discussion, a highly intelligent student can take the discussion beyond the intellectual level of the less able.

- It needs substantial extra effort in preparation, working with students individually, and simultaneously monitoring multiple groups or activities within the classroom.

- There is a danger of overrating neat and well-presented work, while it is pedestrian in content, due to the striking contrast with the struggling efforts of the less able.

While not refuting the prevalence of physical and mental elimination in inclusive classes as presumed by Fuchs et al. (1993), it can be argued that this phenomenon is a result of the teachers' ineptitudeness in handling 
diversity among students, and not a result of malfeasance imbedded in inclusion as suggested by proponents of ability grouping. If this is the case, students should not be denied valuable learning experiences in order to cover up for the teachers' lack of appropriate teaching skills.

\subsubsection{Organisational and instructional strategies}

Basic to inclusion, is the idea that teachers will be in a position to tailor lessons to individual levels of the students in their classes (Dean 1997). Dean contends that if done according to book, this can be an effective method of classroom instruction. However, it is rarely, if ever, successful. Most often, teachers end up slowing down their instruction so that all of their students can keep up. In an inclusive class, the range of students' cultural and experiential backgrounds, knowledge and skills to which a conventional teacher must respond to is both breathtaking and befuddling. An unavoidable pedagogical question is how the teacher can reach out to everyone? Dean (1997) thinks that the teacher does not reach all the students. In fact, inherent in an inclusive class is what Gerber and Semmel (1984) refer to as a zero-game. By design, in the zero-game, there will be losers and winners. Gerber and Semmel (1984:141) are of the view that: “. . . teachers aim their instruction 'plans' at. . . relatively homogeneous groups in an apparent attempt to reduce the sheer cognitive complexity of planning and instruction associated with broad ranges of student characteristics and abilities." In an attempt to tackle what teachers view as the impossible, they may choose whom they will and will not teach. They may concentrate on those who require the most help, with the assumption that the more able will find their footing. The other alternative is that they can resort to the accepted medical strategy of triage, which dictates that help is afforded to those having greater chances of survival in the long run. If the observation by Gerber and Semmel (1984) holds water, one may assume that students at both extremes of the ability continuum are not adequately catered for academically. One may also conclude that teachers create homogeneity by design, by eliminating difficult-to-teach children.

Harlen (1997) alludes to the above postulation in her argument that at times inclusive classes are treated as low-ability streams; teachers frequently use whole-class teaching methods, which are inappropriate for such classes. Such classes are hard to manage. Inclusion is problematic in subjects that require correct answers and a grasp of abstract concepts and where all students have to learn the same material before they can move on (Green 2001).

The fact that inclusion poses a number of challenges, which if not properly addressed may result in negative learning outcomes is uncontested. However, teachers should view the students' cultural, experiential background, knowledge and skill diversity as offering opportunities for effective instruction, rather than as causing pedagogical problems. One can also conclude that contrary to the axiom that inclusion narrows the curriculum, it exposes students of different abilities to the curriculum material they could have been exposed to in any other grouping systems, all other things being equal.

\subsubsection{Affective and social outcomes}

Inclusion may have a negative impact on the self-esteem of low achievers. According to Loveless (1999), the inclusive classroom may force low achievers into daily comparisons with their more able peers, conditions hostile to the development of self-confidence. She concedes that ability grouping does impact on self-esteem, but it is transitory in nature, as compared to the daily comparisons between high achievers and low achievers in inclusive classes.

Basing on the preceding discussion it seems that the bottom line in the grouping debate seems to be a trade-off between excellence and equity. These terms tend to engender a false dualism in that many seem to speak in terms of having either excellence or equity, but not both. The pro-ability grouping argument has been primarily concerned with the issue of academic excellence, while exponents of inclusion have been concerned with equity. Given this scenario, perhaps the question begging attention is: 'Is it not possible to achieve both equity and excellence without necessarily grouping students according to some perceived intellectual abilities?' Protagonists in the grouping debate had better take heed of Hart's (1998) advice that as they search for effective methods to achieve equity and excellence in education, they should note that it is not the nature of grouping per se which needs to pre-occupy their minds, but rather how learners and their differing attainments are construed, and how these constructions should be used to inform pedagogy. These contested issues: problems of using ability as a basis for grouping, grouping and education of the gifted, and students with learning disabilities and difficulties buttress the call for harnessing students' diversities in order to realise effective instruction.

\section{Research Methodology}

The study adopted a qualitative case study design. Twenty five secondary school teachers were purposively selected from Bulawayo Metropolitan's secondary schools. Focus group discussions were used for data generation. Discussions were recorded verbatim and transcribed. Partial field analysis was done prior to subsequent focus group discussions. Data were verified before the major analysis. Analysis was based on 
grounded theory, which included segmenting, coding and arranging data into themes and sub-themes. Data triangulation could not be done as earlier planned due to time factor. To mitigate any methodological weaknesses, careful considerations were take into account during sampling, to ensure that focus groups were rich in terms of teacher experience, gender, qualifications and subjects being taught.

\section{Findings}

Teachers were aware that (a) their classrooms were populated with diverse students in terms of ability, motivation levels, learning rates, readiness, backgrounds inter alia (b) students' diversities meant that the 'One size fits all approach to teaching' does not work in inclusive classes. They acknowledged the need to use student-centred approaches, as well as varying the approaches owing to different learning styles inherent in students. Some of the teachers' remarks on teaching strategies were that: "Just like the name of what, mixedability, you should mix the teaching approaches . . . in order to cater for all the students"; "...if you are using one method, know that you are disadvantaging other students who are not good at listening. But if you say vary, I feel you will be catering for all the students..."; “... they are time consuming and they need to be varied, need to use a lot of strategies to teach mixed-ability classes. The following teaching strategies resonated during the discussions:

\subsection{Group work.}

The general feeling was that teachers could use group work, whereby students are given tasks to tackle in groups. Students can choose group leaders and secretaries, work on the tasks, record proceedings and report back to the whole class. During group discussions, the teacher could be moving around from group to group, ensuring full participation of members, and clarifying any concepts. One teacher remarked: '. . . if some students are bright and get the point easily, then they can explain the point to their group members while the teacher is helping others'. Teachers pointed out that in smaller groups, shy members of the class may feel confident to contribute. Depending with the nature of the tasks, even those learners considered as academically challenged, using their backgrounds can contribute positively to the accomplishment of the tasks, as stated by one teacher: ' . . . if we are talking about tourism, if a student has been exposed to tourism, the student could use that experience to enrich others'. Yet another one quipped; ' . . . let us say you give them something to discuss on, the highfliers from what the slow learners have presented can benefit'.

\subsection{Project method.}

An appreciable number of teachers mentioned this teaching strategy. However, teachers pointed out that for this method to be successful, the type of tasks involved in the project should be such that all the group members have something to contribute, notwithstanding their academic ability. One teacher gave the following example: ' In Geography for example, the project could be on the school map. At times it may happen that, one of the group members considered as academically challenged, could be good in art. So the group members, including the academically gifted will rely on the group member who is academically challenged but very good in art. At the end, when the project is completed all the students will feel good'.

\subsection{Peer Tutoring.}

This method was also very popular among the teachers who took part in the study. They pointed out that the method benefits both the tutor and the tutee. The tutor benefits in that as he/she explains the concepts to the tutee, he/she clarifies her on reasoning and transfers the information to the long-term memory. The tutee benefits in that, the tutor is likely to explain the concepts using the tutee's language level. The environment will not be threatening, therefore the tutee can ask for clarification, without the fear of being laughed at or ridiculed by the whole class.

\subsection{Discovery Method.}

Most teachers mentioned that discovery method could also be used. They reiterated that it could be used in conjunction with other methods.

The teachers' theoretical knowledge of teaching strategies that can be used to harness students' diversities bodes well for the teaching of such classes. The implication of such knowledge is that with proper support and guidance from their instructional supervisors, teachers can make use of these strategies to teach inclusive classes effectively.

\subsection{Are teachers harnessing students' diversities?}

However, while acknowledging the diversities in their classes, teachers reiterated that they did not always make use of the above methods in their teaching. The frequently mentioned reasons for the non-use of teaching methods that harness students' diversities were: 
- Time factor versus syllabi coverage;

- The demanding nature of student-centred teaching methods;

- Resource availability;

- Nature of student assessment - teachers claimed that it encouraged rote learning and memorising facts for regurgitation during examinations; and

- Teachers' limited repertoire of teaching skills.

The challenges mentioned by teachers are a cause for concern. It was evident that while teachers were aware of some teaching strategies that could be used to harness students' diversities for effective instruction, teachers were rarely using the suggested strategies. Presently, the teacher education curriculum used in Zimbabwe's teacher training colleges is not pro-inclusion. Therefore, most teachers graduate from teachers' training colleges with some theoretical knowledge on teaching strategies, but being deficient in the practical component. Chances are also high that even the lecturers who taught the teachers during their years at college were also deficient in training skills for inclusive classes. The teaching strategies that were suggested by teachers as being suitable for inclusive classes could have been taught theoretical in professional foundation courses or during in-service training. In essence, the implication is that more often than not, teachers target their teaching to the presumed average child, at the expense of children occupying both extremes of the academic continuum. In also appears as if teachers believe that most student-centred teaching strategies are time consuming and will therefore make it difficult for teachers to complete the syllabi in time for the examinations. There is need to convince teachers that it is possible to cover the syllabi in time for the examinations while using teaching strategies that harness students' diversities. Teachers should teach for understanding, instead of teaching for the examination.

The following conclusions were arrived at:

\section{Conclusion}

- Teachers were not making full use of students' diversities to bring about effective instruction.

- Teachers had some knowledge of strategies that could be used to harness students' diversities for effective instruction.

- Teachers felt that teaching strategies that harness students' diversities are time-consuming such that if they make extensive use of them, they will not complete the syllabi in time for the examinations. Non-use of the strategies can also be attributed to the teachers' limited skills in handling diverse classes.

\section{Recommendations}

Basing on the above, the following recommendations were arrived at:

- There is need for a paradigm shift in teachers' minds concerning what constitutes good teaching. This could be accomplished through in-service training for serving teachers and introducing a pro-inclusive orientated teacher education curriculum.

- At the system's level, the nature of students' assessment should be looked into. Continued use of normreferenced assessment may mean that teachers will carry on employing the maligned teacher-centred teaching approaches.

- The teacher education curriculum needs to be interrogated with the view of making it pro-inclusive so that new entrants into the teaching field enter the arena equipped with the necessary knowledge, skills and attitudes to harness students' diversities for effective instruction.

\section{References}

[1]. Collier, F. (1982). 'A Retreat from Mixed-Ability Teaching', in Sands, M. and Kerry, T. (eds.), Mixed-Ability Teaching, London: Croon Helm.

[2]. Dean, C. (1997). Ability Based Grouping: An Educational Tool of the Devil? http://home.earthlink.net/ifdean (accessed 20 November, 2012).

[3]. Farmer, D. (1996). Ability Grouping Strategies, http://www.austega.com/gifted/child/index.htm (accessed 10 December, 2012).

[4]. Fuchs, D., Fuchs, L. S. and Fernstrom, P. (1993). 'A conservative approach to special education reform: Mainstreaming through transenvironmental programming and curriculum-based assessment', American Educational Research Journal, 7: 120-128.

[5]. Gamoran, A., Nystrand, M., Berends, M. and Lepore, P. C. (1995). 'An Organisational Analysis of the Effects of Ability Grouping', American Educational Research, 32(4): 687-715.

[6]. Gerber, M. M. and Samuel, M. I. (1984). 'Teacher as Imperfect Test: Reconceptualising the Referral Process', Educational Psychologist, 19: 137-148.

[7]. Good, L. T. and Brophy, E. J. (1997). Looking in Classrooms, ( $7^{\text {th }}$ edn.), New York: Longman.

[8]. Green, H. (2001). Success of mixed-ability classes depends on what you teach,

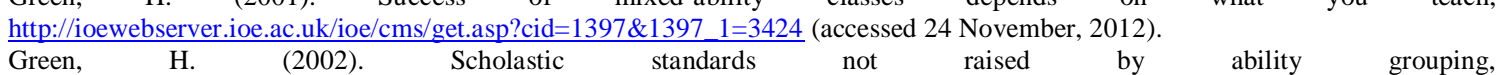

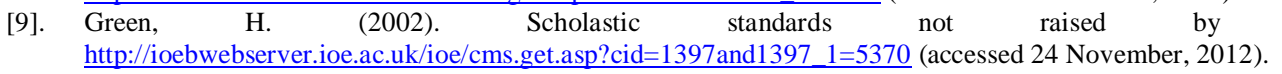

[10]. Hallahan, D. P. and Kauffman, J. M. (1997). Exceptional Learners: An Introduction to Special Education, ( $7^{\text {th }}$ edn.), Boston: Ally and Bacon. 
[11]. Harlen, C. (1997). Making Sense of the Research on Ability Grouping, http://www.scre.ac.uk/ (accessed on 12 December, 2012).

[12]. Ireson, J. and Hallam, S. (2001). Ability Grouping in Education, London: Paul Chapman.

[13]. Killen, R. (2002). Productive Pedagogy. Unpublished manuscript, Australia, University of Newcastle, Faculty of Arts.

[14]. Kulik, J. A. (1992). An Analysis of the Research on Ability Grouping: Historical and Contemporary Perspectives, http://www.ucc.uconn.edu/-wwwgt/kulik.html (accessed 2nd December, 2012).

[15]. Lockwood, J. H. and Cleveland, E. F. (2001). The Challenge of Detracking: Finding the Balance Between Excellence and Equity, http://eric-web.tc.columbia.edu/ (accessed 12 December, 2011).

[16]. Loveless, T. (1999). The Tracking and Ability Grouping Debate, http://www.edexcellence.net/fordham/foreports.html (accessed 29 November, 2012).

[17]. Mann, D. (2002). Why Ability Grouping Widens the Academic Achievement Gap, http://educationright.tripod.com/id23.htm (accessed 24 November, 2012).

[18]. Marcus, L. R. and Johnson, T. (1998). New Possibilities for Teaching Diverse Populations in Tomorrow's High Schools, horizon.unc.edu/projects/HSJ/Marcus.asp-30k (accessed on 10 December, 2012).

[19]. National Association of School Psychologists (2002). Position Statement on Ability Grouping, http://www.naspoline.org/information/pospaper-ag.html (accessed 26 November, 2012).

[20]. Oakes, J. (1992). 'Can tracking research inform practice? Technical, Normative and Political Considerations', Educational Researcher, 21(4): 12-21.

[21]. Oakes, J. and Lipton, M. (1999). 'Access to Knowledge: Challenging the Techniques, Norms and Politics of Schools', in Sirotnik, A. K. And Soder, R. (eds.), The Beat of A Different Drum: Essays on Educational Renewal in Honour of John. I. Goodlad, New York: Peter Lang, 131-151.

[22]. Reid, I. M., Clunies,-Ross, L. R., Goacher, B. and Vile, C. (1981). Mixed-Ability Teaching: Problems and Possibilities, Windsor: The NFER-Nelson.

[23]. Riehl, C. J. (2000). 'The Principal's Role in Creating Inclusive School for Diverse Students: A Review of Normative, Empirical, and Critical Literature on the Practice of Educational Administration', Educational Researcher, 70(1): 55-81.

[24]. Shield, M. C. (1996). 'To Group or Not to Group Academically Talented or Gifted Students?', Educational Administration Quarterly, 32(2): 295-323.

[25]. Slavin, R. E. (1994). Educational Psychology, (4 ${ }^{\text {th }}$ edn. $)$, Boston: Allyn and Bacon.

[26]. Susan, A. (1991). 'Ability Grouping Research Reviews: What Do They Say About Grouping and the Gifted?', Educational Leadership, 60-64.

[27]. Vivian, M. (2001). Facing the Challenges of Mixed Ability Classes, http://www.linguastrangeira.pro.br/artigos_papers/mixed.htm (accessed 10 December, 2012).

[28]. Wilson, R. A. (1998). Special Educational Needs in the Early Years, London: Routledge. 